\title{
Çevresel şartların tek tesirli yapışma bağlantılı kompozitler üzerinde etkisi
}

\section{The Effects of Environmental Conditions on Single-Lap Adhesively Bonded Composites}

\author{
Gurbet Örçen $^{1 *}$, Engin Koyun ${ }^{2}$ \\ ${ }^{1}$ Dicle Üniversitesi, Makina Mühendisliği Bölümü, Diyarbakır, gurbetorcen@ dicle.edu.tr \\ ${ }^{2}$ Dicle Üniversitesi, Makina Mühendisliği Bölümü, Diyarbakır, engin.kyun@ gmail.com
}

\begin{tabular}{|c|c|}
\hline MAKALE BİLGİLERİ & ÖZET \\
\hline Makale geçmişi: & \multirow{7}{*}{$\begin{array}{l}\text { Fiber takviyeli kompozitlerin birçok alanda kullanımları giderek artmaktadır. Bu alanlarda kullanımı etkileyen } \\
\text { çevresel şartlar, kompozitlerin dayanımları ve bağlantı performansları üzerindeki etkilerinin anlaşılması } \\
\text { açısından önemlidir. Ayrıca daha uygun tasarımların oluşmasında da etkin rol oynamaktadırlar. } \\
\text { Bu çalışmada, farklı bindirme uzunlukları ve fiber takviye açılarına sahip, tek tesirli bindirme yapışma bağlantılı } \\
\text { kompozitlerin hidrotermal ortamda davranışları incelenmiştir. Bu davranışları tahmin etmek için } 40^{\circ} \mathrm{C}, 60^{\circ} \mathrm{C} \text { ve } \\
80^{\circ} \mathrm{C} \text { sabit bir su sıcaklığında ve değişken daldırma periyodlarında }(15 \text { gün, } 30 \text { gün ve } 45 \text { gün }) \text { bir deneysel } \\
\text { çalışma gerçekleştirilmiştir. Fiber takviye açıları }\left[0^{\circ}\right]_{8} \text { ve }\left[45^{\circ} /-45^{\circ} / 0^{\circ} / 90^{\circ}\right]_{\mathrm{s}} \text { olan cam epoksi kompozit levhalar } \\
\text { kullanılmıştır. Bu iki levhadan bindirme uzunlukları } 25 \mathrm{~mm} \text { ve } 35 \mathrm{~mm} \text { olan numuneler hazırlanmıştır. } \\
\text { Hidrotermal ortama yerleştirilen bu numunelerden, emilim oranları, hasar yükleri ve hasar tipleri elde edilmiştir. } \\
\text { Bu sonuçlar kendi aralarında ve oda sıcaklığında bekletilen numuneler ile karşılaştırılmıştır. } \\
\text { Bu çalışmada; }\left[45^{\circ} /-45^{\circ} / 0^{\circ} / 90^{\circ}\right]_{\mathrm{s}} \text { fiber dizilimli numunelerden elde edilen hasar yük değerlerinin, }\left[0^{\circ}\right]_{8} \text { fiber } \\
\text { dizilimli numunelerden elde edilen değerlerden daha düşük olduğu tespit edilmiştir. En düşük hasar yük } \\
\text { değerleri, } 80^{\circ} \mathrm{C} \text { sicaklığa maruz kalan numunelerden elde edilmiştir. Tüm numunelerin hidrotermal ortamda } \\
\text { bekleme süresi ve ortamın sıcaklığı arttığ1 zaman hasar yüklerinin düştüğü ancak nem emilim oranlarının arttığ1 } \\
\text { tespit edilmiştir. Buna bağli olarak, genel olarak hasar tiplerinde, fiber hasarı ve yapıştırıcı hasarı beraber elde } \\
\text { edilmiştir. }\end{array}$} \\
\hline Geliş: 07 Ocak 2021 & \\
\hline Düzeltme: 8 Şubat 2021 & \\
\hline Kabul: 8 Şubat 2021 & \\
\hline Anahtar kelimeler: & \\
\hline $\begin{array}{l}\text { Tek tesirli bağlantı, yapışma } \\
\text { bağlantı, hidrotermal etki, hasar }\end{array}$ & \\
\hline & \\
\hline
\end{tabular}

Doi: 10.24012/dumf.855501

\begin{tabular}{|c|c|}
\hline ARTICLE INFO & ABSTRACT \\
\hline & \multirow{7}{*}{$\begin{array}{l}\text { The use of fiber-reinforced composites is increasing in many application areas. Environmental conditions that } \\
\text { affect usage in these areas are important to understand the effects of composites on their strength and bonding } \\
\text { performance. They also play an effective role in creating more suitable designs. } \\
\text { In this study, the behaviors of single lap adhesively bonded composite joint which has different lap lengths and } \\
\text { different fiber reinforcement angles are investigated in the hydrothermal environment. To predict these } \\
\text { behaviors, an experimental study was carried out at a constant water temperature of } 40^{\circ} \mathrm{C}, 60^{\circ} \mathrm{C} \text { and } 80^{\circ} \mathrm{C} \text { and } \\
\text { variable immersion periods ( } 15,30 \text { and } 45 \text { days). Glass epoxy composite plates with fiber reinforcement angles } \\
{\left[0^{\circ}\right]_{8} \text { and }\left[45^{\circ} /-45^{\circ} / 0^{\circ} / 90^{\circ}\right]_{\mathrm{s}} \text { were used. Specimens with lap lengths of } 25 \mathrm{~mm} \text { and } 35 \mathrm{~mm} \text { were prepared from }} \\
\text { these two plates. Absorption rates, failure loads and failure modes were obtained from these specimens placed in } \\
\text { hydrothermal environment. These results were compared with each other and with specimens kept at room } \\
\text { temperature. } \\
\text { In this study; it has been determined that the failure load values obtained from specimens with the fiber sequence } \\
{\left[45^{\circ} /-45^{\circ} / 0^{\circ} / 90^{\circ}\right]_{s} \text { are lower than the values obtained from specimens with the fiber sequence }\left[0^{\circ}\right]_{8} \text {. The lowest }} \\
\text { failure load values were obtained from specimens exposed to a temperature of } 80{ }^{\circ} \mathrm{C} \text {. It was determined that } \\
\text { when the waiting time of all specimens in the hydrothermal environment and the temperature of the environment } \\
\text { increased, the failure loads decreased but the moisture absorption rates increased. Accordingly, in general, in } \\
\text { failure modes, fiber failure and adhesive failure were achieved together. }\end{array}$} \\
\hline Received: 7 January 2021 & \\
\hline February 2021 & \\
\hline Accepted: 8 February 2021 & \\
\hline Keywords: & \\
\hline $\begin{array}{l}\text { Single-lap joint, adhesively } \\
\text { bonded, hydrothermal effect, } \\
\text { failure load, composite materials }\end{array}$ & \\
\hline & \\
\hline
\end{tabular}

* Sorumlu yazar / Correspondence

Gurbet ÖRÇEN

$\bowtie$ gurbetorcen@dicle.edu.tr

Please cite this article in press as G. Örçen, E.Koyun, "Hidrotermal şartların tek tesirli bindirme yapışma bağlantılı kompozitler üzerindeki etkisi”, DUJE, vol. 12 no. 2 , pp. 263-273, March 2021. 


\section{Giriș}

Kompozit yapılarda yapıştırıcı yardımıyla yapılan bağlantıların; uygun tasarım esnekliği, geometrileri, yük taşıma kapasiteleri, düşük maliyet, hafiflik vb. özelliklerinden dolayı pimli/civatalı vb. bağlantılara göre kullanımları artmıştır. Yapıştırıcı yardımıyla yapılan bağlantılarda, geometrik parametreler (yapıştırıcı kalınlığı, bindirme uzunluğu, bağlantı konfigürasyonu), malzeme parametreleri (yapıştırıcı ve yapışkan malzeme), çevresel parametreler (bağlantı öncesi ve bağlantı sonrası nem, sıcaklık, ıslaklık), üretim yöntemi, yüzey hazirlama ve hasar tipleri gibi parametreler yapıların performansını doğrudan veya dolaylı olarak etkilemektedirler [1]. Bu parametrelerin bağlantı mukavemeti üzerindeki etkisi ile ilgili literatürde birçok çalışma yapılmıştır. Özellikle kompozit-kompozit ile yapilan tek tesirli yapışma bağlantıları ile ilgili deneysel [2,4-6, 8, $9,11,15-21-28,32]$ ve sayisal [1-5,7-14,20] çalışmalar yapılmıştır. Sanz ve arkadaşları [2]; yapışkan bölge modeli (CZM) kullanılarak, tek eksenli çekme yüküne maruz kalan, tek tesirli yapışma bağlantılarının mekanik dayanımı üzerinde; yapıştırıcı ve yapıştırıcının geometrisindeki değişikliklerin etkilerini Abaqus/Standard' ta değerlendirmişlerdir. Yea ve arkadaşları [3], farklı bindirme uzunluklarına sahip tek tesirli yapışma bağlantılı kompozitlerde üç boyutlu (3D) sonlu elemanlar metodu ve deneysel yöntemlerle hasar davranıșlarını incelemişlerdir. Silva ve Adams [4], düşük sicaklıktan yüksek sicaklığa doğru dayanıklılık için iki yapıştırıcı kombinasyonu ile uygun bir bağlantıyı araştırmışlardır. Özel ve arkadaşları [5], çekme yükü altında alt ve üst yapışkanların farklı konfigürasyonları ile tek tesirli yapışma bağlantısının mekanik özelliklerini araştırmışlardır. Neto ve arkadaşları [6], farklı yapıştırıcı ve farklı bindirme uzunlukları ile bağlantısı yapılmış tek tesirli yapışma bağlantısında dayanım ve hasar prosesi açısından bir karekterizasyon belirlemeye çalışmışlardır. Lin ve arkadaşları [7], yapıştırıcı ile bağlantısı yapılmış CFRP bağlantılarında, bindirme uzunlukları, yapışma kalınlığı gibi parametreleri seçerek gerilme performansını araştırmışlardır. Magalhaesa ve arkadaşları [8], tek tesirli yapışma bağlantılı tabakalı kompozitlerde gerilme konsantrasyon etkilerini iki boyutlu sonlu eleman yöntemi ile araştırmışlardır.

Tek tesirli bindirme bağlantılı kompozitlerde, bağlantıların güvenliğini sağlamak için, çevresel şartların etkisini ve özellikle hidrotermal etkiyi anlamak oldukça önemlidir [16-28,32]. Bu alanda deneysel olarak çalışma yapan bazı araştırmacilardan; Barker [16]; epoksi yapıştırıcılarla bağlanmış CFRP-CFRP bağlantılarının dayanımı ve hasar tipleri üzerinde sıcak ve nemli ortamın etkisini araştırmıştır. Hem nem emiliminin hem de test sicaklığının artırılmasıla bağlantıların dayanımının düştügünü belirtmiştir. Armstrong [17]; farklı yapıştırıcı tipleri kullanılarak yapıştırılan CFRP kompozitlerin kuru hallerini ve su içerisinde bekletilerek performanslarını araştırmıştır. Performansın uzun süreli beklemelerde düştüğünü ve hasar tiplerini etkilediğini belirtmiştir. Park ve arkadaşları [18], tek tesirli bindirme bağlantılı karbon epoksi kompozitlerin dayanımları üzerinde çevresel şartların etkisini araştırmışlardır. Yüksek sıcaklık ve nemin tabakanın mukavemetini artırdığını ancak yapışkan kayma mukavemetini azalttığını belirtmişlerdir. Taib ve arkadaşları [19]; tek tesirli bindirme bağlantıların dayanımı üzerinde; yapıştırıcı kalınlığı, bağlantı geometrisi ve nem etkilerini araştırmışlardır. Soykok [20] ise yapıştırıcı yardımıyla elde edilmiş tek tesirli cam fiber takviyeli epoksi kompozitlerin belli sıcaklık aralıklarına sahip su içindeki davranışlarını araştırmıştır. $\mathrm{Su}$ emiliminin mukavemeti azalttığını belirtmiştir. Assarar ve arkadaşları [23], keten ve cam fiber takviyeli kompozitlerin mekanik özellikleri üzerinde suyun etkisini incelemişlerdir. Suda kalma süresi arttıkça keten fiber kompozitlerin çekme modülü çok az etkilenirken, cam fiber takviyeli kompozitlerin çekme mukavemetinde düşüş olduğunu belirtmişlerdir. Zhang ve arkadaşları [24], yapıştırıcı yoluyla yapılan bağlantılarda kullanılan iki farklı epoksi bazlı yapıştırıcının; $80{ }^{\circ} \mathrm{C}-90{ }^{\circ} \mathrm{C}$ ile $80{ }^{\circ} \mathrm{C}-95{ }^{\circ} \mathrm{C}$ aralığındaki nem emilimlerini ve mekanik davranışlarını incelemişlerdir. Nem ve sicaklık etkisinin, yapıştırıcının çekme ve kayma özellikleri üzerinde olumsuz etkisi olduğunu belirtmişlerdir. Bellini ve arkadaşları [25], iki farklı yapıştırıcı ile üretilen tek tesirli yapışma bağlantılı CFRP numunelerin mekanik dayanımları üzerinde, $\quad-28 \quad{ }^{\circ} \mathrm{C}$ ile $\quad 85{ }^{\circ} \mathrm{C}$ 
sıcaklığına sahip hava, damıtılmış su ve tuzlu suyun etkisini incelemişlerdir [25]. Ayrıca 25 ${ }^{\circ} \mathrm{C}, 70{ }^{\circ} \mathrm{C}$ ve $120{ }^{\circ} \mathrm{C}$ sicakliklarda çekme testine tabi tutmuşlardır [26]. Her iki tip yapıştırıcının damıtılmış suyun içerisinde yaşlanma sonrası elde edilen ortalama gerilmelerinin birbirine yakın olduğunu belirtmişlerdir [25]. Alarcon ve arkadaşları [27], tek tesirli bağlantılı kompozit numuneleri 9 ay ve 12 ay boyunca doğal yaşlandırmaya tabi tutarak, yapıştırıcı ve bağlantı üzerindeki etkisini incelemişlerdir. Doğal yaşlanma sürecinde yapıştırıcı ve tek tesirli bağlantının mekanik özelliklerinde düşüş olduğunu belirtilmişlerdir. Mariam ve arkadaşları [28], yapıştırma yoluyla tek tesirli olarak elde edilen cam fiber takviyeli epoksi kompozitlerin, $50{ }^{\circ} \mathrm{C}$ 'lik sıcak suyun içerisinde $20,40,60,80,100$ ve 120 gün bekleterek etkilerini araştırmışlardır. Sicak suda bekleme süresi artıkça dayanımlarının düştüğünü belirtmişlerdir.

Literatürde görüldüğü gibi nem veya sicaklığın yapışma bağlantıları üzerindeki etkisi incelenmiştir. Ancak bu iki etkinin aynı anda hareket etmesi durumunda elde edilen sonuçlar her zaman net değildir. $\mathrm{Bu}$ birleşik etkinin incelenmesi, daha fazla araştırma yapılması gereken bir konudur [25]. Bağlantı ve yapıştırıcı dayanımı ile hasar davranışları üzerinde bu etkinin anlaşılması ve aynı zamanda uygulama alanlarına yönelik çözümler sunulması önemlidir.

$\mathrm{Bu}$ çalışmamızda çevresel şartlardan olan hidrotermal ortamın, farklı fiber dizilimlerine sahip tek tesirli bindirme bağlantılı kompozit numunelerin hasar davranışları üzerindeki etki seviyesi incelenmiştir. Üç farklı sıcaklığa sahip suyun içerisinde yine üç farklı bekleme zamanı içerisinde bekletilen numunelerden elde edilen hasar yükleri, hasar tipleri ve emilim oranlarının sonuçları karşılaştırılmıştır.

\section{Deneysel Metot}

$\mathrm{Bu}$ çalışmada $\left[0^{\circ}\right]_{8}$ örgülü (woven) ve $[45 \%$ $\left.45^{\circ} / 0^{\circ} / 90^{\circ}\right]_{\text {s }}$ dizilimlere sahip cam fiber takviyeli epoksi kompozit levhalar, İzoreel Tic. A.Ş. firmasından elde edilmiştir. Kompozit levhaların kalınlığı (t) $2 \mathrm{~mm}$ olarak üretilmiştir. Her iki fiber dizilimine sahip kompozit levhalardan; levha uzunluğu $(\mathrm{L}=175 \mathrm{~mm})$ ve levha genişliği $(\mathrm{w}=30 \mathrm{~mm})$ ölçülerinde numuneler kesilmiştir
(Şekil 1.a). $\mathrm{Bu}$ numunelerden, bindirme mesafeleri $\left(l_{b}\right) ; 25 \mathrm{~mm}$ ve $35 \mathrm{~mm}$ olmak üzere tek tesirli bindirme bağlantıları elde edilmiştir (Şekil 1.b). Her numuneden üçer adet hazırlanmış olup, lb: 25 mm' lik bağlantıdan 60 adet ve $l_{b}$ : 35 mm' lik bağlantıdan da 60 adet olmak üzere, toplamda 120 adet numune hazırlanmıştır. Eğilme etkisini en aza indirgemek, gerilme yığılmalarını önlemek için aynı malzemeden kesilen sekmeler, numune uçlarına yapıştırıcı yardımıyla yapıştırılmış.

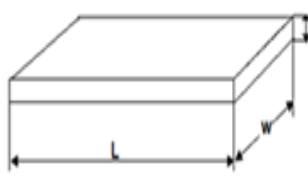

(a)

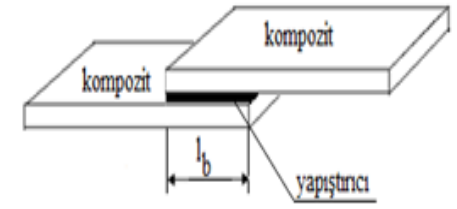

(b)
Şekil 1.(a) Levha numunesinin geometrik ölçüleri. (b)Tek tesirli bindirme bağlantılı numunelerin geometrik ölçüleri.

Figure 1.(a) Geometric dimensions of the plate specimen. (b) Geometric dimensions of specimens with single-lap adhesively bonded.

Tek tesirli bindirme bağlantılı numuneler elde edilirken, yapıştırılacak yüzeylerin yüzey temizliği ASTM D2093-03 [29], standardına göre gerçekleştirilmiştir. Çalışmada yapıştırıcı olarak, Loctite EA 9466 tipindeki epoksi yapıştırıcı kullanılmıştır. Yapıştırıcı kalınlığı tüm ișlemlerde $0,25 \mathrm{~mm}$ olarak alınmıștır. Yapıștırıcı kalınlığının tüm numunelerde aynı olabilmesi için, yapıştırma işlemi için özel kalıplar imal edilmiștir. Şekil 2 ' de görülen bu kalıplar 3D printer cihazıyla üretilmiștir. Yapıştırıcı yardımıyla elde ettiğimiz $\left[0^{\circ}\right]_{8}$ ve $\left[45^{\circ} /-45^{\circ} / 0^{\circ} / 90^{\circ}\right]_{\mathrm{s}}$ fiber dizilimli tek tesirli bindirme bağlantılı kompozit numuneler, oda sicaklığında 15 gün süre ile kurumaya bırakılmıştır. Kompozit numuneler, $40{ }^{\circ} \mathrm{C}, 60^{\circ} \mathrm{C}$ ve $80{ }^{\circ} \mathrm{C}$ sicaklığa ayarlı termostatlı sicak su dolu kapalı kazanlarda üç gruba ayrılarak yerleștirilmiştir. Numunelerin kazanlara yerleşimi için ek askılıklar yaptırılmıştır (Şekil $3)$. Her sıcaklıkta 15 gün, 30 gün ve 45 gün süre ile bekletilmişlerdir. 


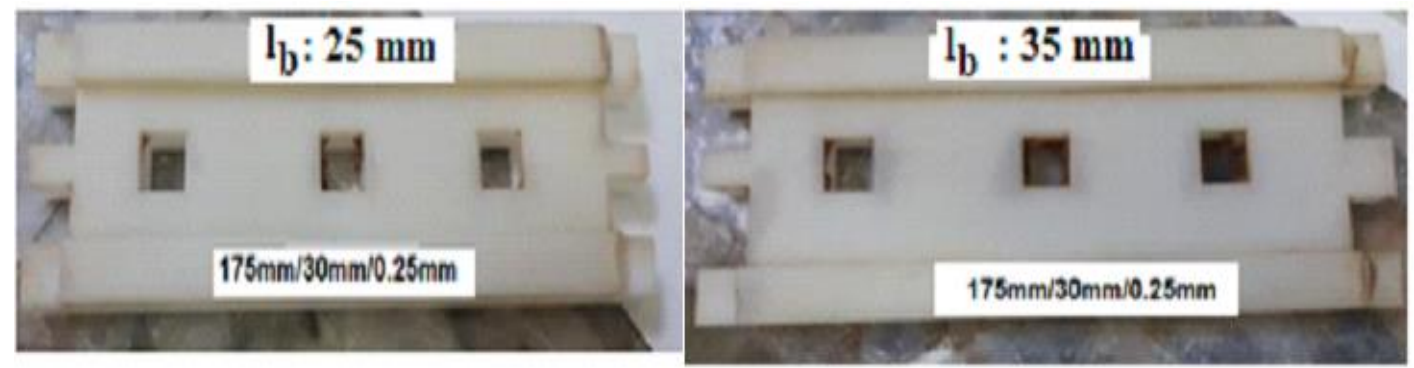

Şekil 2. $l_{b}=25 \mathrm{~mm}$ ve $l_{b}=35 \mathrm{~mm}$ için üretilen kalıplar

Figure 2.Molds produced for $l_{b}=25 \mathrm{~mm}$ and $l_{b}=35 \mathrm{~mm}$

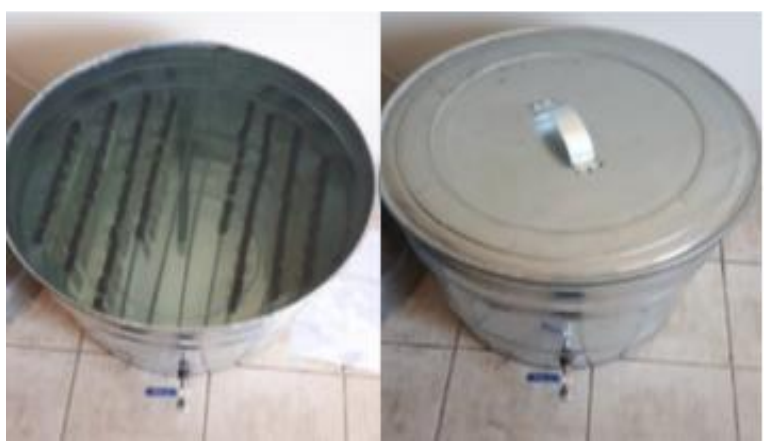

Şekil 3. Numuneler için hazırlanan termostatlı kazanlar

Figure 3. Thermostat boilers prepared for specimens

Süre bitiminde numuneler sudan çıkartılıp, üzerlerindeki fazla su silinerek, hassas terazide tartılmış ve bir saat içerisinde çekme testine tabi tutulmuşlardır. Çekme testi; instron marka, 100 $\mathrm{kN}$ 'luk test cihazında, $1 \mathrm{~mm} / \mathrm{dk}$ hızında yapılmıştır. Aynı zamanda kuru haldeki cam

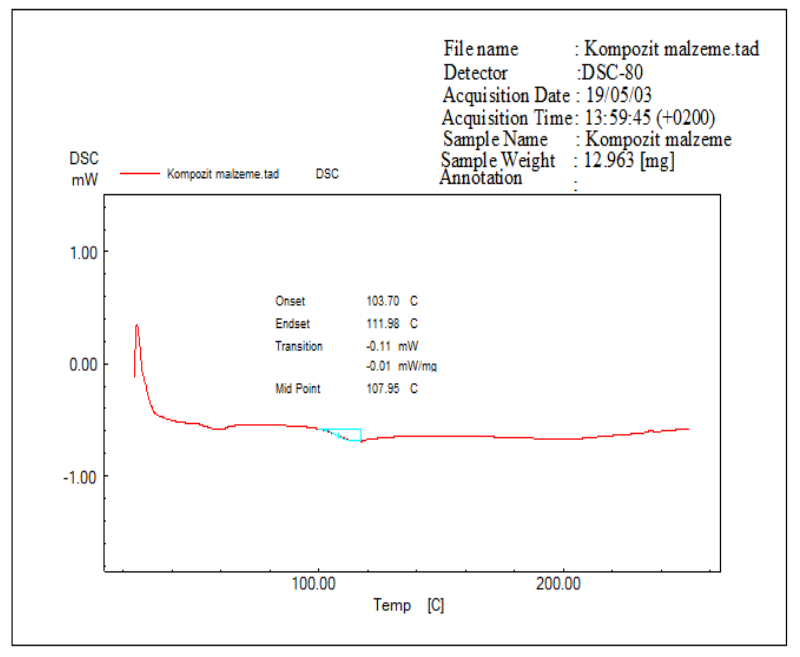

(a) fiber takviyeli kompozit malzemenin ve Loctite EA 9466 tipindeki yapıştırıcının camsı geçiş sicaklıkları DSC analizi ile sirasiyla; $107,95{ }^{\circ} \mathrm{C}$ ve $54,52{ }^{\circ} \mathrm{C}$ olarak tespit edilmiştir (Şekil $4(a),(b))$.

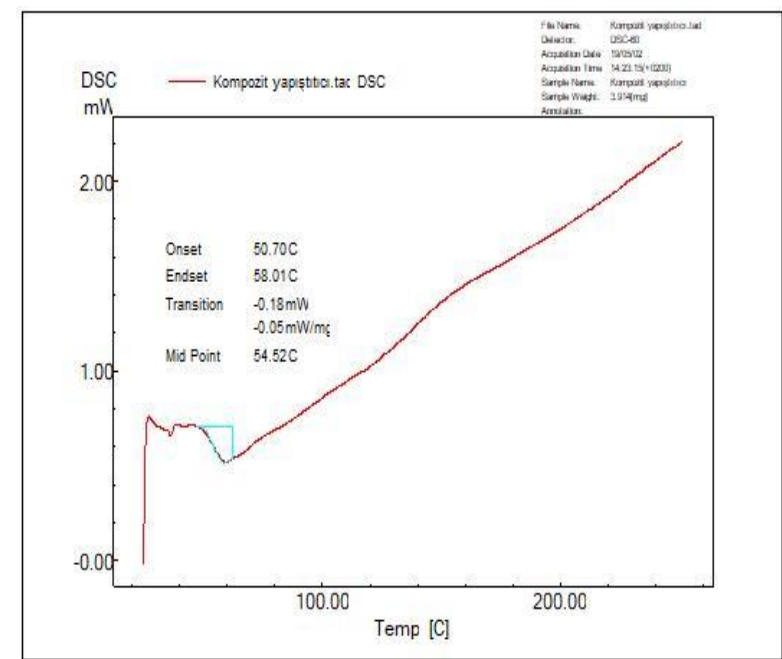

(b)

Şekil 4. (a) Kompozit malzemenin [33]

(b) Yapıştırıcının $T_{g}$ sicakliğg tespiti

Figure 4.(a)Composite materials[33]

(b) Adhesive Tg temperature detection 


\section{Sonuçlar ve Tartışma}

\section{Hidrotermal ortamın emilim oranları üzerine etkisi}

Her numunenin; sıcak su kazanına konulmadan önceki ilk ağırlıkları $\left(\mathrm{w}_{\mathrm{o}}\right)$ ve sudan çıkarıldıktan sonraki ağırlıkları $\left(\mathrm{w}_{\mathrm{s}}\right)$, 0,01 gr kapasiteli hassas terazi ile ölçülmüştür. Böylelikle her numunenin nem emilim oranı $\left(\mathrm{M}_{\mathrm{t}}\right)$ aşağıdaki formülasyon ile hesaplanmıştır.

$\mathrm{M}_{\mathrm{t}}=\left[\left(\mathrm{w}_{\mathrm{s}}-\mathrm{w}_{\mathrm{o}}\right) / \mathrm{w}_{\mathrm{o}}\right] \mathrm{x} 100$

Her numuneden üçer adet üretildiği için ortalama değer alınarak, numunelerin nem emilim oranları Tablo 1' e aktarılmıştır. Birçok polimerik matris kompozit; su ortamlarına maruz kaldığında, önce yüzey emilimi ve daha sonrada matris içinden difüzyonla nemi emmektedirler. Epoksi matrisli kompozitlerde nem konsantrasyonu başlangıçta zamanla artmakta ve nemli ortamlara maruz kaldıktan bir süre sonra doygunluk seviyesine yaklaşmaktadır [31]. Tablo 1 'de görüldüğü gibi suda bekleme zamanı arttıkça nem emilim oranının arttığ görülmektedir. Suyun reçine matrisine daha fazla sızmas1, nem emme hassasiyeti, yüksek sicaklıklarda daha da artmaktadır [1]. Bu durum fiber takviyeli kompozitler içinde su moleküllerinin yayılabilirliğinde belirleyici bir rol oynadığını göstermektedir [20]. Burada da en fazla emilim oranının, $80^{\circ} \mathrm{C}$ sicaklıkta bekletilen numunelerden elde edildiği tespit edilmiştir.

Tablo 1. Numunelerin nem emilim oranları (\%)

Table 1. Moisture absorption rates of specimens (\%)

\begin{tabular}{cccccc}
\hline & \multicolumn{2}{c}{$1_{\mathrm{b}}: 25 \mathrm{~mm}$} & \multicolumn{2}{c}{$1_{\mathrm{b}}: 35 \mathrm{~mm}$} \\
\hline \multirow{2}{*}{ Su sicaklığ1 } & Süre(gün) & {$\left[0^{0}\right]_{8}$} & {$\left[45^{0} /-45^{0} / 0^{0} / 90^{0}\right]_{\mathrm{s}}$} & {$\left[0^{0}\right]_{8}$} & {$\left[45^{0} /-45^{0} / 0^{0} / 90^{0}\right]_{\mathrm{s}}$} \\
\hline \multirow{2}{*}{$40{ }^{\circ} \mathrm{C}$} & 15 & 0,35 & 1,74 & 0,58 & 1,59 \\
& 30 & 0,63 & 1,85 & 0,7 & 1,81 \\
& 45 & 0,8 & 2,03 & 1,74 & 1,85 \\
\hline \multirow{2}{*}{$60{ }^{\circ} \mathrm{C}$} & 15 & 0,38 & 2,17 & 0,36 & 1,25 \\
& 30 & 0,58 & 2,48 & 1,21 & 1,42 \\
& 45 & 0,68 & 2,69 & 1,66 & 1,94 \\
\hline \multirow{2}{*}{$80{ }^{\circ} \mathrm{C}$} & 15 & 0,95 & 3,23 & 1,21 & 3,45 \\
& 30 & 1,08 & 3,67 & 1,24 & 3,57 \\
& 45 & 1,53 & 3,71 & 1,6 & 3,71 \\
\hline
\end{tabular}

Tablo 1' den de görüldüğü gibi $l_{b}=25 \mathrm{~mm}$ ve $\mathrm{l}_{\mathrm{b}}=35 \mathrm{~mm}$ olan $\left[45^{\circ} /-45^{\circ} / 0^{\circ} / 90^{\circ}\right]_{\mathrm{s}}$ fiber dizilimine sahip numunelerden elde edilen emilim oranlarının, aynı geometrideki $\left[0^{\circ}\right]_{8}$ fiber dizilimine sahip numunelerden elde edilen emilim oranlarından daha fazla olduğu hesaplanmıştır. $\mathrm{l}_{\mathrm{b}}=25 \mathrm{~mm}$ olan $\left[45^{\circ} /-45^{\circ} / 0^{\circ} / 90^{\circ}\right]_{\mathrm{s}}$ dizilimli numunelerden elde edilen emilim oranlarının, $\left[0^{\circ}\right]_{8}$ dizilimli numunelerden elde edilen emilim oranlarına göre minimum 2,42 ile maksimum 5,71 katı kadar daha fazla gerçekleştiği tespit edilmiştir.

Hidrotermal ortamın hasar yükleri üzerine etkisi
Yüksek sıcaklık ve yüksek nem konsantrasyonunun bir arada olması kompozit malzemelerin yük-uzama davranışlarını etkilemektedir [1]. Şekil 5' te örnek olarak en fazla emilimin olduğu $\left[45^{\circ} /-45^{\circ} / 0^{\circ} / 90^{\circ}\right]_{\mathrm{s}}$ dizilimli gruptaki numunelerin yük-uzama grafikleri toplu olarak verilmiştir. [45\%$\left.45^{\circ} / 0^{\circ} / 90^{\circ}\right]_{\mathrm{s}}$ dizilimli bu gruptaki numunelerin uzama oranlarının, sıcaklık derecesi ve emilim oranları arttıkça genelde düştüğü görülmektedir.

$l_{b}=25 \mathrm{~mm}$ 'de $40{ }^{\circ} \mathrm{C}$ ve $60{ }^{\circ} \mathrm{C}$ ' de 15 gün ve 30 gün süre ile bekletilen numunelerde hasar yükleri düșerken, uzama miktarının kuru numuneye göre arttığı görülmektedir. $l_{b}=35 \mathrm{~mm}$ ' 
deki numunelerde kuru numuneye göre hem uzama miktarı hem de hasar yüklerinde düşüş olarak görülmektedir. Dolayısıyla başlangıçtaki emilim oranı ile daha sonraki emilim oranları arasındaki fark, uzama miktarı arasında küçük farkla da olsa kendini gösterdiği grafiklerde de görülmektedir.
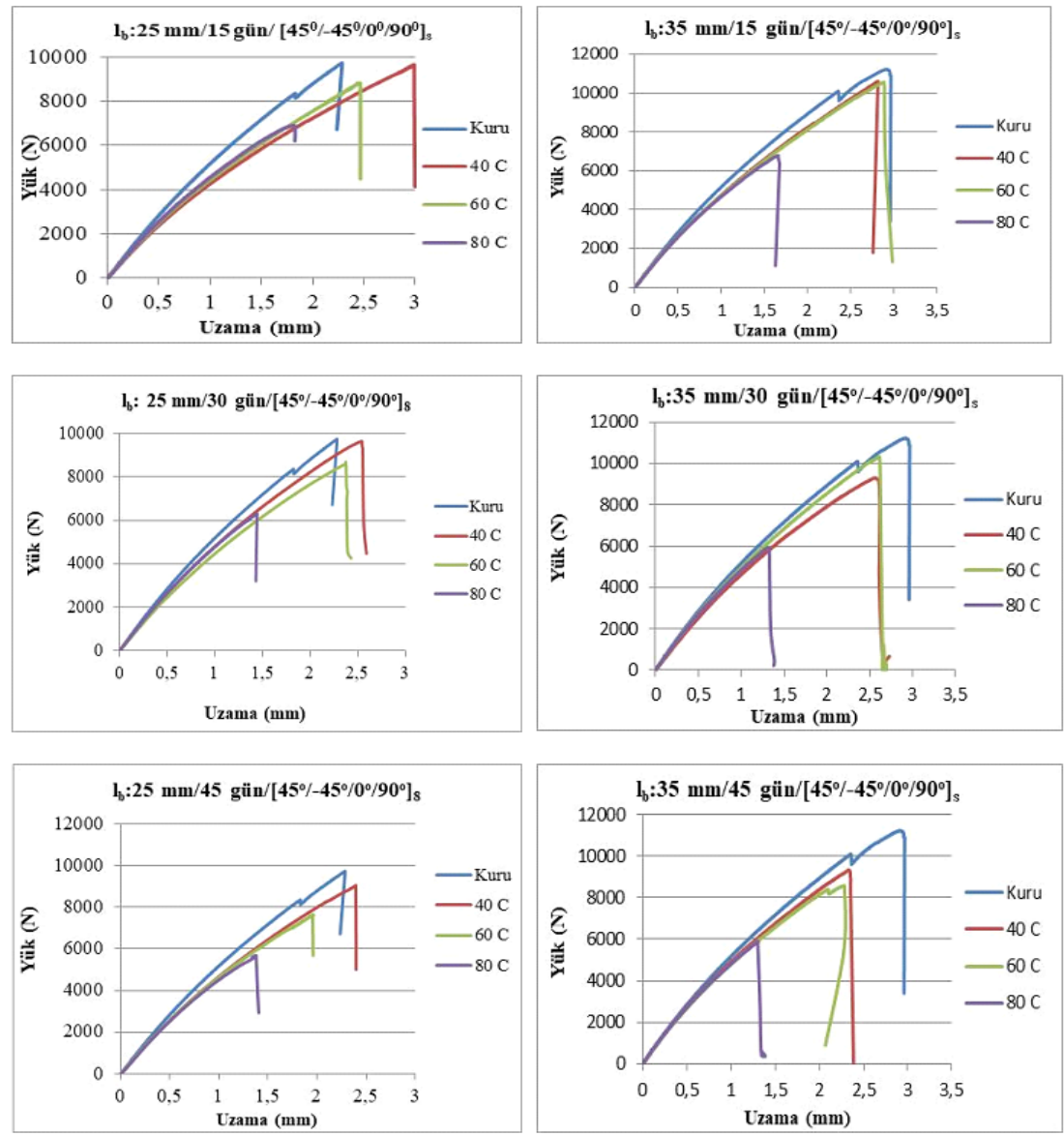

Şekil 5. $l_{b}=25 \mathrm{~mm}, l_{b}=35 \mathrm{~mm}$ numunelerin fiber dizilimine göre yük-uzama grafikleri

Figure 5.Load-elongation graphs based on fiber sequence of $l_{b}=25 \mathrm{~mm}, l_{b}=35 \mathrm{~mm}$ specimens

Kompozit tabakalarda su emiliminin, matrisin plastikleşmesi, polimerik zincirlerin kırılmasıyla moleküler bozulma, şişme ve iç gerilmeler, su durumunun değișmesi nedeniyle çatlama ve yapışma konusu ile ilgili fiber/matrix arayüzünde oluşan hasarlar üzerinde etkilidir [32]. Nem emiliminin artmas1 ile fiber matriks ara yüzeylerinde ve bağlantı bölgelerinde hasar olarak kendini göstermekte ve daha fazla hasarlı yapıya yol açmaktadır [1]. Dolayısı ile en fazla nem emilim oranının gerçekleştiği [45\%$\left.45^{\circ} / 0^{\circ} / 90^{\circ}\right]_{\mathrm{s}}$ dizilimli numunelerde bağlantı mukavemetinde düşüş olarak görülmektedir (Tablo 2). $\left[0^{\circ}\right]_{8}$ fiber dizilimine sahip cam fiber takviyeli epoksi $\left(l_{b}=25 \mathrm{~mm}\right)$ kompozit numunelerin; $80^{\circ} \mathrm{C}$ 'lik suda 45 gün bekletildiğinde elde edilen hasar yük değerinin, $60{ }^{\circ} \mathrm{C}$ ve $40{ }^{\circ} \mathrm{C}$ 'lik suda 45 gün bekletilenlere göre sirasiyla \%18,91 ve \%26,62 oranlarında daha düşük olduğu tespit edilmiştir (Tablo 2). Bu durum aynı bağlantı mesafesine sahip $\left[45^{\circ} /-45^{\circ} / 0^{\circ} / 90^{\circ}\right]_{\text {s }}$ fiber dizilimli numunelerde; $80{ }^{\circ} \mathrm{C}^{6}$ lik suda 45 gün bekletildiğinde elde edilen hasar yük değerinin, $60{ }^{\circ} \mathrm{C}$ ve $40{ }^{\circ} \mathrm{C}$ 'lik suda 45 gün bekletilenlere göre sirasıyla \% 34,33 ve \%58,99 oranlarında daha düşük olduğu tespit edilmiştir (Tablo 2, Şekil 6) . 
Tablo 2. Bekleme zamanı ve sıcaklığa bağlı olarak elde edilen hasar yük değerleri Table 2. Failure load values obtained depending on waiting time and temperature

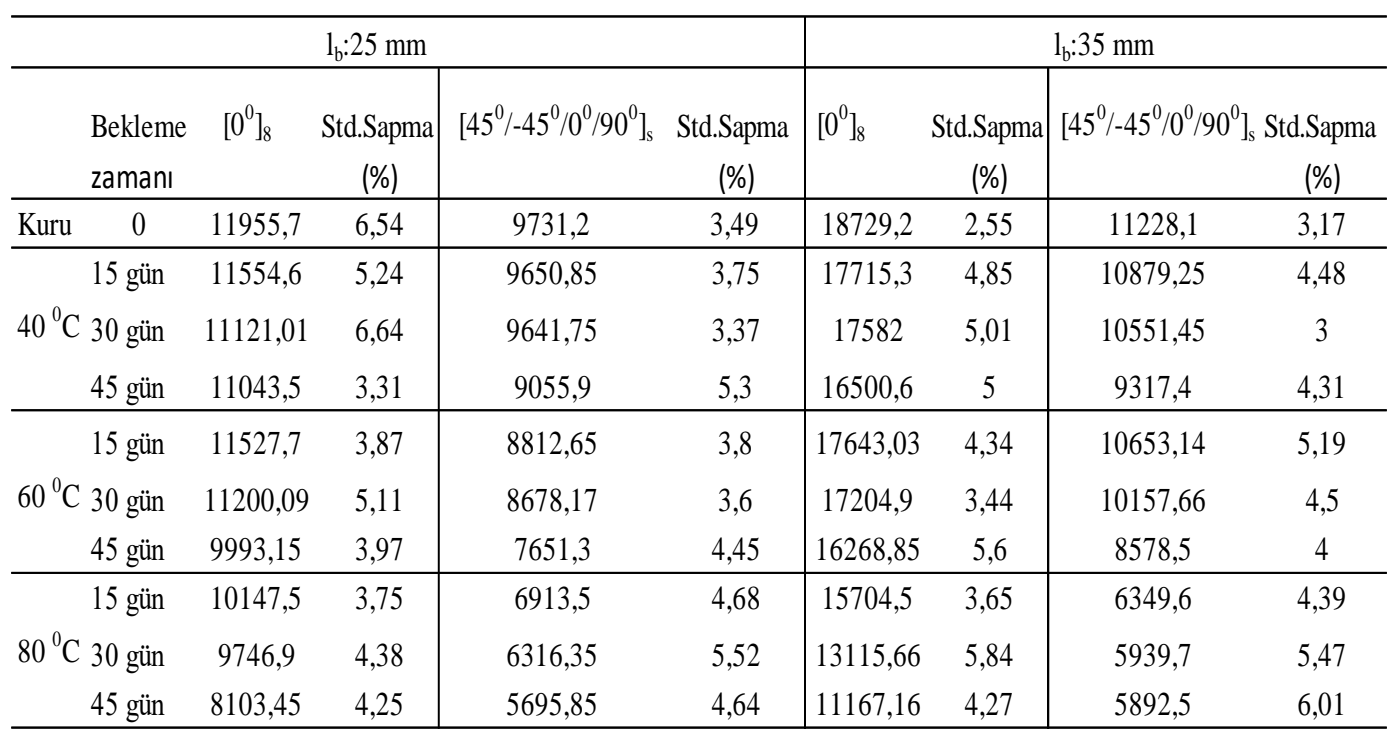

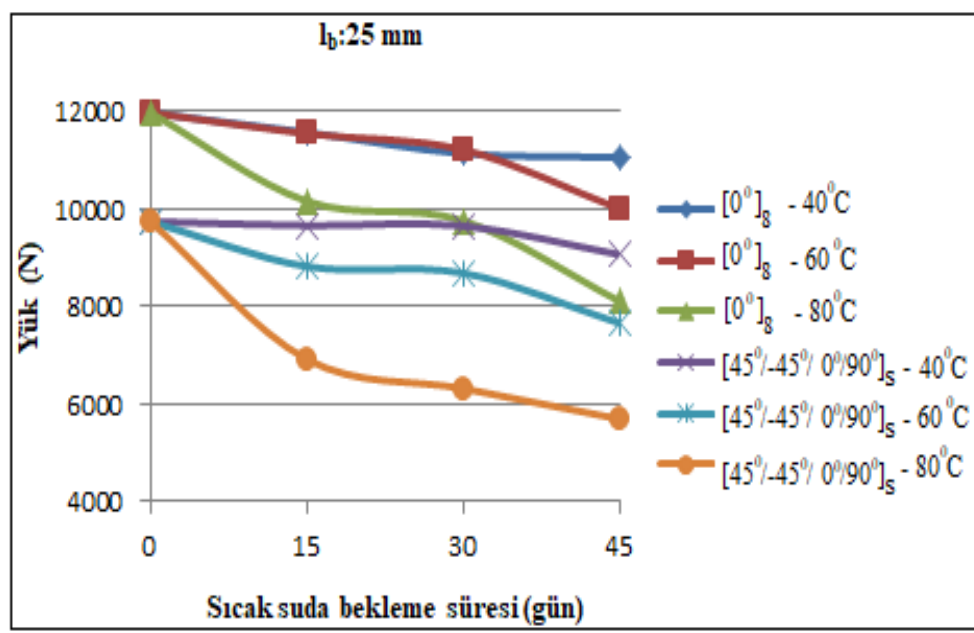

Şekil 6. $l_{b}=25 \mathrm{~mm}$ için, bekleme zamanı ve sıcaklığın hasar yükleri üzerindeki etkisi

Figure 6. Effect of waiting time and temperature on failure loads for $l_{b}=25 \mathrm{~mm}$

Bindirme mesafesi uzunluğu arttığ 1 zaman $\left(l_{b}\right.$ $=35 \mathrm{~mm}$ ), hasar yüklerinde de artış beklenen bir sonuçtur. Ancak sicaklık derecesi ve bekleme zamanına bağlı olarak elde edilen değerler arasındaki orana baktığımız zaman $\left[0^{\circ}\right]_{8}$ fiber dizilimine sahip numuneler, 30 gün boyunca 80 ${ }^{\circ} \mathrm{C}$ sicaklikta bekletildiğinde elde edilen yük değeri; $60{ }^{\circ} \mathrm{C}, 40{ }^{\circ} \mathrm{C}$ sicaklıkta aynı süre ile bekletildiğinde ve kuru haldeki numunelerden elde edilen yük değerine göre sirasıyla $\% 23,77$,
$\% 25,40$ ve $\% 29,97$ oranlarında düştüğü görülmüştür. Aynı bekleme zamanında [45\%$\left.\begin{array}{lll}45^{\circ} & / 0^{\circ} / 90^{\circ}\end{array}\right]_{s}$ fiber dizilimli numunelerde ise 80 ${ }^{\circ} \mathrm{C}$ sicaklıkta bekletildiğinde elde edilen yük değeri; $60{ }^{\circ} \mathrm{C}, \quad 40{ }^{\circ} \mathrm{C}$ sicaklıkta aynı süre ile bekletildiğinde ve kuru haldeki numuneden elde edilen yük değerine göre sirasıyla \%41,52, \% 43,71 ve $\% 47,10$ oranlarında düştüğü tespit edilmiştir (Tablo 2, Şekil 7). 


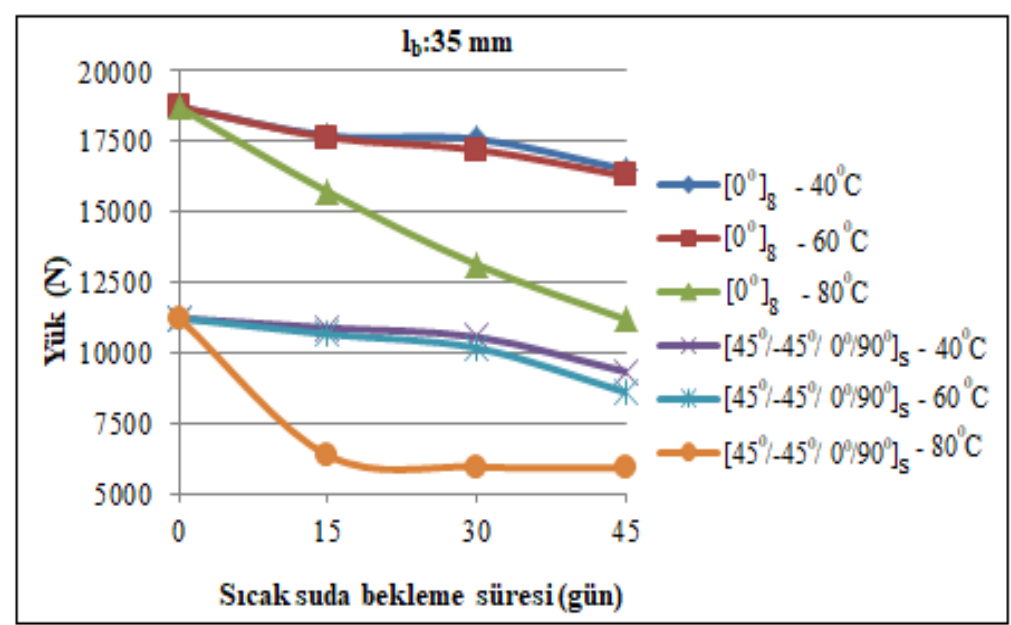

Şekil 7. $l_{b}=35 \mathrm{~mm}$ için, bekleme zamanı ve sıcaklı̆̆ın hasar yükleri üzerindeki etkisi

Figure 7. Effect of waiting time and temperature on failure loads for $l_{b}=35 \mathrm{~mm}$

Elde edilen deneysel sonuçlarla; hidrotermal ortamın yapışma yoluyla yapılan bağlantılarda bağlantı bölgesini, kompozit malzeme dayanımını etkilediği ve malzeme dayanımının düştüğü görülmektedir. Dolayısıyla bu sonucun $16,20,25,28$ ve 32 nolu referans çalışmalarıyla uyumlu olduğu gözlemlenmiştir.

\section{Hidrotermal ortamın hasar tipleri üzerine etkisi}

Bindirme mesafeleri, fiber dizilimleri, bekleme süresi ve sicaklığa bağlı olarak elde edilen hasar tipleri Tablo 3'te verilmiştir. Hızlı bir şekilde yapışkan ara yüzeye yayılan nem etkisi, daha sonra bir kimyasal reaksiyonu tetiklemekte ve bunun sonucunda yapışma ayrışmalarına neden olmaktadır [28]. Bu durum numunelerin hasar tiplerinde, fiber hasarı $(\mathrm{FH})$, yapıştırıcı hasarı $(\mathrm{YH})$, malzeme hasarı $(\mathrm{MH})$, az fiber hasarı (LFH) ya da her ikisinin görüldüğü karma hasar tipi $(\mathrm{FH}+\mathrm{YH}, \mathrm{LFH}+\mathrm{YH})$ olarak elde edilmiştir (Tablo 3).

Tablo 3. Numune geometrine bağll elde edilen hasar tipleri

Table 3.Failure modes obtained depending on the specimen geometry

\begin{tabular}{|c|c|c|c|c|c|c|c|c|c|c|c|}
\hline Numune geometrisi & Fiber dizilimi & & & $40^{\circ} \mathrm{C}$ & & & $60^{\circ} \mathrm{C}$ & & & $80^{\circ} \mathrm{C}$ & \\
\hline \multirow{7}{*}{$\mathrm{l}_{\mathrm{b}}: 25 \mathrm{~mm}$} & \multirow{4}{*}[0^{0}]{$_{8}$} & Kuru & 15 gün & 30 gün & 45 gün & 15 gün & 30 gün & 45 gün & 15 gün & 30 gün & 45 gün \\
\hline & & $\mathrm{FH}+\mathrm{YH}$ & $\mathrm{FH}+\mathrm{YH}$ & $\mathrm{FH}+\mathrm{YH}$ & $\mathrm{FH}+\mathrm{YH}$ & $\mathrm{FH}+\mathrm{YH}$ & $\mathrm{FH}+\mathrm{YH}$ & $\mathrm{FH}+\mathrm{YH}$ & $\mathrm{LFH}+\mathrm{YH}$ & Y.H & $\mathrm{MH}$ \\
\hline & & $\mathrm{FH}+\mathrm{YH}$ & $\mathrm{FH}+\mathrm{YH}$ & $\mathrm{FH}+\mathrm{YH}$ & $\mathrm{FH}+\mathrm{YH}$ & $\mathrm{FH}+\mathrm{YH}$ & $\mathrm{FH}+\mathrm{YH}$ & $\mathrm{FH}+\mathrm{YH}$ & $\mathrm{LFH}+\mathrm{YH}$ & $\mathrm{LFH}+\mathrm{YH}$ & MH \\
\hline & & $\mathrm{FH}+\mathrm{YH}$ & $\mathrm{FH}+\mathrm{YH}$ & $\mathrm{FH}+\mathrm{YH}$ & $\mathrm{FH}+\mathrm{YH}$ & $\mathrm{FH}+\mathrm{YH}$ & $\mathrm{FH}+\mathrm{YH}$ & $\mathrm{FH}+\mathrm{YH}$ & $\mathrm{LFH}+\mathrm{YH}$ & $\mathrm{FH}+\mathrm{YH}$ & $\mathrm{MH}$ \\
\hline & \multirow{3}{*}[45^{0}/-45^{0}/0^{0}/90^{0}]{$_{\mathrm{s}}$} & $\mathrm{FH}+\mathrm{YH}$ & $\mathrm{FH}+\mathrm{YH}$ & $\mathrm{FH}+\mathrm{YH}$ & $\mathrm{FH}+\mathrm{YH}$ & $\mathrm{FH}+\mathrm{YH}$ & M.H & $\mathrm{FH}+\mathrm{YH}$ & M.H & M.H & $\mathrm{LFH}+\mathrm{YH}$ \\
\hline & & $\mathrm{FH}+\mathrm{YH}$ & $\mathrm{FH}+\mathrm{YH}$ & $\mathrm{FH}+\mathrm{YH}$ & $\mathrm{FH}+\mathrm{YH}$ & M.H & M.H & $\mathrm{FH}+\mathrm{YH}$ & M.H & M.H & $\mathrm{LFH}+\mathrm{YH}$ \\
\hline & & $\mathrm{FH}+\mathrm{YH}$ & $\mathrm{FH}+\mathrm{YH}$ & M.H & $\mathrm{FH}+\mathrm{YH}$ & $\mathrm{FH}+\mathrm{YH}$ & $\mathrm{LFH}+\mathrm{YH}$ & $\mathrm{FH}+\mathrm{YH}$ & M.H & M.H & $\mathrm{LFH}+\mathrm{YH}$ \\
\hline \multirow{6}{*}{$\mathrm{l}_{\mathrm{b}}: 35 \mathrm{~mm}$} & \multirow{3}{*}[0^{0}]{$_{8}$} & $\mathrm{FH}+\mathrm{YH}$ & $\mathrm{FH}+\mathrm{YH}$ & $\mathrm{FH}+\mathrm{YH}$ & $\mathrm{FH}+\mathrm{YH}$ & $\mathrm{FH}+\mathrm{YH}$ & $\mathrm{FH}+\mathrm{YH}$ & $\mathrm{FH}+\mathrm{YH}$ & $\mathrm{FH}+\mathrm{YH}$ & $\mathrm{FH}+\mathrm{YH}$ & $\mathrm{FH}+\mathrm{YH}$ \\
\hline & & $\mathrm{FH}+\mathrm{YH}$ & $\mathrm{FH}+\mathrm{YH}$ & $\mathrm{FH}+\mathrm{YH}$ & $\mathrm{FH}+\mathrm{YH}$ & $\mathrm{FH}+\mathrm{YH}$ & $\mathrm{FH}+\mathrm{YH}$ & $\mathrm{FH}+\mathrm{YH}$ & $\mathrm{FH}+\mathrm{YH}$ & $\mathrm{LFH}+\mathrm{YH}$ & $\mathrm{FH}+\mathrm{YH}$ \\
\hline & & $\mathrm{FH}+\mathrm{YH}$ & $\mathrm{FH}+\mathrm{YH}$ & $\mathrm{FH}+\mathrm{YH}$ & $\mathrm{FH}+\mathrm{YH}$ & $\mathrm{FH}+\mathrm{YH}$ & $\mathrm{FH}+\mathrm{YH}$ & $\mathrm{FH}+\mathrm{YH}$ & $\mathrm{FH}+\mathrm{YH}$ & $\mathrm{FH}+\mathrm{YH}$ & $\mathrm{FH}+\mathrm{YH}$ \\
\hline & \multirow{3}{*}[45^{0}/-45^{0}/0^{0}/90^{0}]{$_{\mathrm{s}}$} & $\mathrm{FH}+\mathrm{YH}$ & $\mathrm{FH}+\mathrm{YH}$ & M.H & M.H & M.H & $\mathrm{FH}+\mathrm{YH}$ & $\mathrm{FH}+\mathrm{YH}$ & Y.H & $\mathrm{LFH}+\mathrm{YH}$ & M.H \\
\hline & & $\mathrm{FH}+\mathrm{YH}$ & $\mathrm{FH}+\mathrm{YH}$ & M.H & M.H & M.H & M.H & M.H & M.H & M.H & M.H \\
\hline & & $\mathrm{FH}+\mathrm{YH}$ & M.H & M.H & M.H & M.H & M.H & M.H & M.H & M.H & M.H \\
\hline
\end{tabular}


Elde edilen hasar tiplerinden bazıları örnek olarak Şekil 8'de verilmiştir. Nem emiliminin matris malzemesinin bütünlüğüne zarar verirken, özellikle camsı geçiş sıcaklığı üzerinde daldırıldığında epoksi matris malzemesi için daha şiddetli olduğu görülmektedir [20]. En yüksek sicaklığın $80{ }^{\circ} \mathrm{C}$ olduğu bu çalışmada kompozitin camsı geçiş sicaklığına (tg=107,85 ${ }^{0} \mathrm{C}$ ) yaklaşılmış ancak yapıştırıcının camsı geçiş sicaklığ $\left(\operatorname{tg}=54,52{ }^{\circ} \mathrm{C}\right)$ aşılmıştır. Su emilimi yapıştırıcının fiziksel ve mekanik özelliklerini önemli ölçüde etkileyebilmektedir [28]. Yapıştırıcı ile birleştirilmiş numunelerin bağlantı bölgelerindeki mukavemet ile kompozit malzeme mukavemeti hem sicaklik hem de nem emilimi ile etkilenmiştir. Hidrotermal ortamın numuneler üzerinde oluşturduğu hasarlar göz önüne alındığında, yapıștırıcı ve bağlantı bölgesi dişında özellikle $80{ }^{\circ} \mathrm{C}$ sicaklıkta kompozit malzemede hasarlar oluştuğu tespit edilmiştir.
$\mathrm{Bu}$ oluşan hasar, malzeme kırılması hasarı $(\mathrm{MH})$ olarak elde edilmiştir. Bu hasar kompozit tabakanın aşırı bozulmasının, epoksi matrisindeki kalıcı bir kimyasal değișiklikten kaynaklanmaktadır [20]. Özellikle [45\%$\left.45^{\circ} / 0^{\circ} / 90^{\circ}\right]_{\mathrm{s}}$ dizilimli, $\mathrm{l}_{\mathrm{b}}=25 \mathrm{~mm}$ ve $\mathrm{l}_{\mathrm{b}}=35 \mathrm{~mm}$ olan numunelerde daha fazla gözlemlenmiştir. Tablo 1 ve Tablo $3^{6}$ teki veriler karşılaştırıldığında; $80{ }^{\circ} \mathrm{C}$ sıcaklıkta 45 gün bekletildiğinde $\% 3,71,30$ günde $\% 3,57,15$ günde ise $\% 3,45$ olarak gerçekleşen nem emilim oranlarında, M.H. tipi elde edilmiştir. Benzer durum $40{ }^{\circ} \mathrm{C}$ ve $60{ }^{\circ} \mathrm{C}$ sicakliklarda ayn fiber dizilimli numunelerde de ortaya çıkmıştır.

Elde edilen bu hasar tipinin, Soykok [20] tarafindan yapılan çalışma sonucu ile uyumlu olduğu görülmüş̧ür.

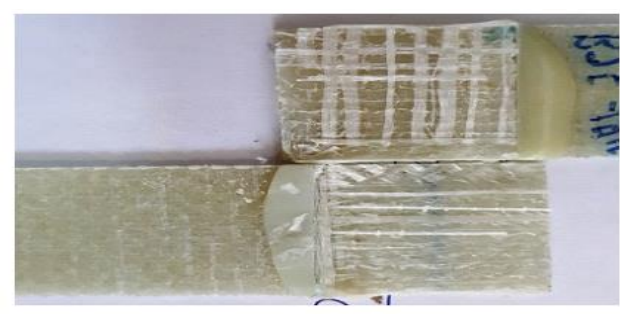

a) $1_{\mathrm{b}}=25 \mathrm{~mm} /\left[45^{\circ} /-45^{\circ} / 0^{\circ} / 90^{\circ}\right]_{\mathrm{s}} / 15$ gün $/ 40^{\circ} \mathrm{C} / \mathrm{FH}+\mathrm{YH}$

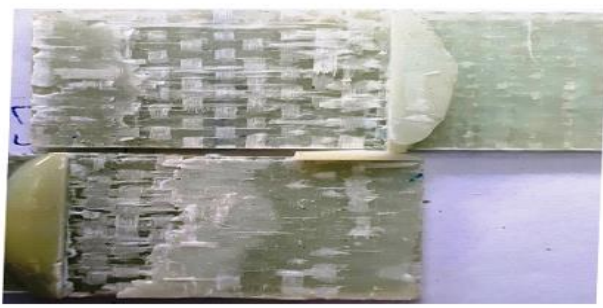

c) $1_{\mathrm{b}}=35 \mathrm{~mm} /\left[0^{\circ}\right]_{8} / 15$ gün $/ 40^{\circ} \mathrm{C} / \mathrm{FH}+\mathrm{YH}$

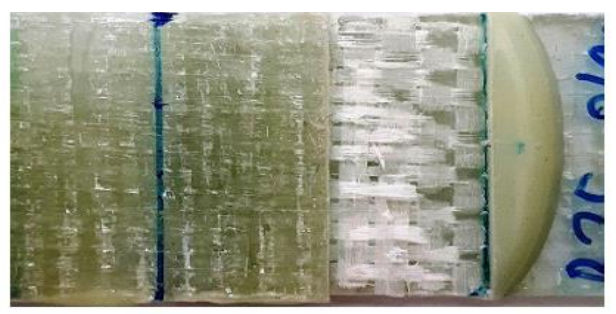

b) $1_{b}=25 \mathrm{~mm} /\left[0^{0}\right]_{8} / 15$ gün $/ 40^{\circ} \mathrm{C} / \mathrm{F} . \mathrm{H}+\mathrm{Y} . \mathrm{H}$

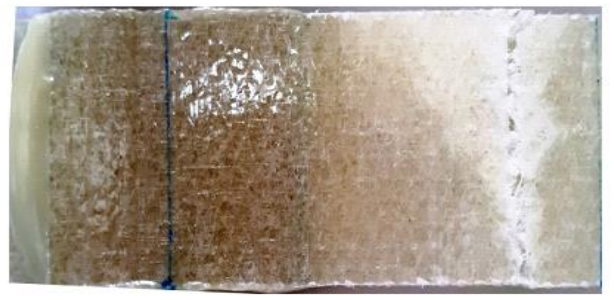

d) $\mathrm{l}_{\mathrm{b}}=35 \mathrm{~mm} /\left[45^{\circ} /-45^{\circ} / 0^{\circ} / 90^{\circ}\right]_{\mathrm{s}} / 15 \mathrm{gün} / 60^{\circ} \mathrm{C} / \mathrm{M} . \mathrm{H}$

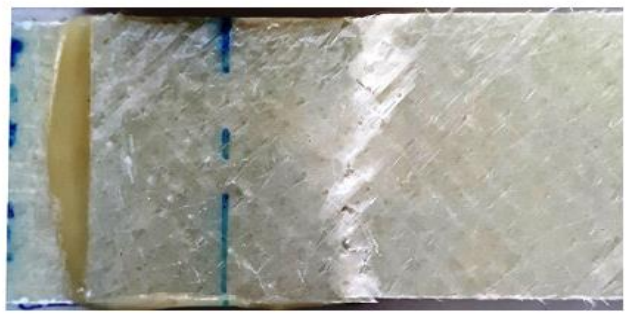

e) $\mathrm{l}_{\mathrm{b}}=25 \mathrm{~mm} /\left[45^{\circ} /-45^{\circ} / 0^{\circ} / 90^{\circ}\right]_{\mathrm{s}} / 15$ gün $/ 80^{\circ} \mathrm{C} / \mathrm{M}$.H

Şekil 8. Hasar tiplerine ait örnekler

Figure 8. Examples of failure modes 


\section{Sonuçlar}

Tek tesirli bindirme yapışma bağlantılı (lb:25 $\mathrm{mm}$ ve $\left.\mathrm{l}_{\mathrm{b}}: 35 \mathrm{~mm}\right),\left[0^{\circ}\right]_{8}$ ve $\left[45^{\circ} / 45^{\circ} / 0^{\circ} / 90^{\circ}\right]_{\mathrm{s}}$ fiber dizilimli cam fiber takviyeli epoksi kompozit numuneler $40{ }^{\circ} \mathrm{C}, 60{ }^{\circ} \mathrm{C}$ ve $80{ }^{\circ} \mathrm{C}$ sicaklıkta, 15 gün, 30 gün ve 45 gün süre ile bekletilmiştir. Sicaklık ve nemin birleşik etkisinin numunelerin emilim oranları, hasar yükleri ve hasar tipleri üzerindeki etkisi incelenmiştir. Yapılan çalışmada;

-Kuru haldeki numunelerin dayanımlarının, sıcaklık ve neme maruz birakılan numunelerin dayanımlarından daha yüksek olduğu tespit edilmiştir.

-Bekleme süreleri ve sicaklıklar göz önüne alındığında, en düşük hasar yük değerleri; 45 gün süre ile $80^{\circ} \mathrm{C}$ suda bekletilen numunelerden elde edilirken, $40^{\circ} \mathrm{C}$ suda 15 gün süre bekletilen numunelerden de en yüksek hasar yük değerleri elde edilmiştir.

$-\left[0^{\circ}\right]_{8}$ fiber dizilimine sahip numunelerden elde edilen hasar yük değerlerinin, $\left[45^{\circ} /-45^{\circ} / 0^{\circ} / 90^{\circ}\right]_{\mathrm{s}}$ numunelerden elde edilen değerlerden daha yüksek olduğu tespit edilmiştir.

-Numunelerden en fazla karma $(\mathrm{FH}+\mathrm{YH})$ hasar tipi elde edilmiştir.

-Suyun sicaklık derecesi ile numunelerin bu ortamda bekletilme süreleri arttığı zaman, nem emme oranlarının arttığ fakat numunelerin dayanımlarının düştüğü tespit edilmiştir.

-Bu anlamda yapıştırıcı ile yapılan kompozit bağlantılar bu çevresel şartlar göz önünde bulundurularak tasarlanmalıdırlar.

\section{Teșekkürr}

Bu çalışma, DÜBAP, MÜHENDİSLIKK.17.018 numaralı proje desteği ile yapılmıştır.

\section{Kaynaklar}

[1] Budhea, S., Baneaa, M.D., Barrosa, S., Silva,L.F.M., "An updated review of adhesively bonded joints in composite materials", International Journal of Adhesion \& Adhesives, 72, 30-42.2017.

[2] Sanz E.M.M., Ivañez I., Garcia-Castillo, S. K., "Effect of the geometry in the strength of single-lap adhesive joints of composite laminates under uniaxial tensile load", International Journal of Adhesion \& Adhesives, 72, 23-29, 2017.

[3] Yea J., Yan Y., Lia J., Honga Y., Tiana Z.,"3D explicit finite element analysis of tensile failure behavior in adhesive bonded composite single-lap joints", Composite Structures, 201, 261-275,2018.

[4] Silva L. F.M., Adams R.D.,'Joint strength predictions for adhesive joints to be used over a wide temperature range", International Journal of Adhesion \& Adhesives, 27, 362-379,2007.

[5] Ozel A., Yazici B., Akpinar S., Aydin M. D., Temiz S., "A study on the strength of adhesively bonded joints with different Adherends", Composites: Part B, 62, 167-174,2014.

[6] Neto J.A.B.P., Campilho R.D.S.G., Silva L.F.M., "Parametric study of adhesive joints with composites", International Journal of Adhesion \& Adhesives, 37, 96-101,2012.

[7] Lin J., Yan Y., Zhang T., Liang Z., "Experimental study of adhesively bonded CFRP joints subjected to tensile loads", International Journal of Adhesion \& Adhesives, 57, 95-104,2015.

[8] Magalhaesa A.G., Mourab M.F.S.F., Gonc-alves J.P.M., "Evaluation of stress concentration effects in single-lap bonded joints of laminate composite materials", International Journal of Adhesion \& Adhesives, 25, 313-319,2005.

[9] Turan K., Pekbey Y., "Progressive failure analysis of reinforced- adhesively single-lap joint", The Journal of Adhesion, 91:962-977,2015.

[10] Hunter R., Ibacache N., Möller J., Betancourt R., Mora T., Diez E. \& Pavez B., "Influence of Roughness on the Mechanical Adhesion of Single Lap Joints", The Journal of Adhesion, 88:376390,2012 .

[11] Rao, M.V., Rao, K.M., Raju, R.C., Murthy, V.B., Raju V.V.S., "Analysis of Adhesive Bonded Single Lap Joints in Hybrid Composites Subjected to Transverse Load With LC-US End Conditions", International Journal of Theoretical and Applied Mechanics, Vol: 4 (1), 39-48,2009.

[12] Apalak, Z. G., Apalak, M. K and Genç, M., “ Progressive Damage Modeling of an Adhesively Bonded Unidirectional Composite Single - lap Joint in Tension at the Mesoscale Level", Journal of Thermoplastic Composite Materials, (19),671702,2006 .

[13] Luo, Q., and Tong, L., “Analytical Solutions for Nonlinear Analysis of Composite Single-Lap Adhesive Joints", International Journal of Adhesion \& Adhesives, 29: 144-154,2009. 
[14] Her, S.C., "Stress Analysis of Adhesively bonded Lap Joints", Composite Structures, 47, 673$678,1999$.

[15] Panigrahi S.K., Pradhan B., "Through-the-width delamination damage propagation characteristics in single-lap laminated FRP composite joints", International Journal of Adhesion \& Adhesives, 29, 114-124,2009.

[16] Parker B.M., "Some effects of moisture on adhesivebonded CFRP-CFRP joints", Composite Structures, Vol:6, 1-3, Pages 123-139,1986.

[17] Armstrong K.B., "Effect of absorbed water in CFRP composites on adhesive bonding", Int. J. Adhesion and Adhesives , 16, 21-28,1996.

[18] Park Y.B., Song M.G., Kim J.J., Kweon J.H., Choi J.H.,"Strength of carbon/epoxy composite single-lap bonded joints in various environmental conditions", Composite Structures, 92, 2173-2180,2010.

[19] Taib A. A., Boukhili R., Achiou S., Gordon S., Boukehili H.,"Bonded joints with composite adherends. Part I. Effect of specimen configuration, adhesive thickness, spew fillet and adherend stiffness on fracture", International Journal of Adhesion and Adhesives, Vol:26, Issue 4, Pages 226-236,2006.

[20] Soykok I.F., "Degradation of single lap adhesively bonded composite joints due to hot water ageing", The Journal of Adhesion. http://dx.doi.org/10.1080/00218464.2015.1076340., 2015.

[21] Hu P., Han X., Silva L.F.M. , Li W.D., "Strength prediction of adhesively bonded joints under cyclic thermal loading using a cohesive zone model ", International Journal of Adhesion \& Adhesives, 41, 6-15,2013.

[22] Soykok, I.F., Sayman, O., Pasinli, A.," Effects of hot water aging on failure behavior of mechanically fastened glass fiber/epoxy composite joints", Composites: Part B, 54, 59-70,2013.

[23] Assarar, M., Scida, D., El Mahi, A., Poilâne, C., Ayad, R.,"Influence of water ageing on mechanical properties and damage events of two reinforced composite materials: Flax-fibres and glass-fibres", Materials and Design 32, 788-795,2011.

[24] Zhang,J. Cheng,X., Guo,X., Bao,J.,Huang,W., "Effect of environment conditions on adhesive properties and material selection in composite bonded joints", International Journal of Adhesion and

Adhesives, https://doi.org/10.1016/j.ijadhadh.2018.12.001.2018.

[25] Bellini, C., Parodo, G., Polini, W., Sorrentino, L., "Experimental investigation of hydrothermall ageing on single lap bonded CFRP joints", Procedia Structural Integrity ,9, 101-107,2018.

[26] Bellini, C., Parodo, G., Sorrentino, L., "Effect of operating temperature on aged single lap bonded joints", Defence Technology, https://doi.org/10.1016/j.dt.2019.05.015. 2019.

[27] Alarcón, R.A.H., Vizán, A., Peréz, J., Leyrer, J., Hidalgo, P. , Pavez, B., Silva, L.F.M.,"Effect of the natural aging process on the shear strength of FRP composite single lap joints", International Journal of Adhesion and Adhesives, 86,4-12,2018.

[28] Mariam, M., Afendi, M., Abdul Majid, M.S., Ridzuan, M.J.M., Azmi, A.I., Sultan, M.T.H.," Influence of hygrothermal ageing on the mechanical properties of an adhesively bonded joint with different adherends", Composites Part B: Engineering, 165, 572-585,2019.

[29] ASTM Standard D2093-03. 1962,"Standard Practice for Preparation of Surfaces of Plastics Prior to Adhesive Bonding", ASTM International, West Conshohocken, PA, DOI: 10.1520/D209303R11,2011.

[30] ASTM International, Standard Test Method for Moisture Absorption Properties and Equilibrium Conditioning of Polymer Matrix Composite Materials,2004.

[31] P.K.Mallick, Fiber-reinforced composites materials, manufacturing, and design, Second edition, revised and expanded, Marcel Dekker, U.S.A, ISBN: 08247-9031-6, 1993.

[32] Alessi, S., Pitaresi, G., Spadaro, G., "Effect of hydrothermal ageing on the thermal and delamination fracture behaviour of CFRP composites", Composites Part B: Engineering $, 67,145-153,2014$.

[33] Örçen, G., Turan,K., Bingöl,S.,"Mechanical properties of composite plates at different conditions", European Journal of Technique,10(1),2020. 